\title{
Scientific Data in the Ecological Commitment of Young People in the Digital Age
}

\author{
Jocelyn Lachance ${ }^{1^{\star}}$, Mathias Przygoda ${ }^{1}$
}

${ }^{1}$ University of Pau, FRANCE

*Corresponding Author: Jocelyn.lachance@univ-pau.fr

Citation: Lachance, J., \& Przygoda, M. (2021). Scientific data in the ecological commitment of young people in the digital age. Interdisciplinary Journal of Environmental and Science Education, 17(1), e2229. https://doi.org/ 10.29333/ijese/ 9156

\begin{tabular}{ll} 
ARTICLE INFO & ABSTRACT \\
\hline $\begin{array}{l}\text { Received: } \\
27 \text { May 2020 }\end{array}$ & $\begin{array}{l}\text { From } 62 \text { semi-structured interviews carried out with young people ages 14-25 who are engaged in the } \\
\text { defense of the environment, we explored in this article how the circulation of scientific knowledge on the } \\
\text { social media plays a role in engaging young people in defense of the environment to identify how internet } \\
\text { can help to support them. As a result, despite respect for science and scientists, young people's processing } \\
\text { ofcepted: }\end{array}$ \\
$\begin{array}{l}\text { of scientific knowledge does not always seem to respect the standards of objectification advocated by } \\
\text { the scientific approach. This can be problematic because they can appear to be contradictory for their } \\
\text { detractors. Helping them to be more efficient in their active role for promoting environmental issues } \\
\text { means to support them for a more scientific and reflexive use of social media. Thus, the many debates } \\
\text { around environmental education can be enriched by an increasingly precise analysis of the expression of } \\
\text { the commitment of young ecologists on the Internet. }\end{array}$
\end{tabular}

Keywords: commitment, digital era, young people, information, science

\section{INTRODUCTION}

Science plays multiple roles in the public debate on defending the environment. For political decisionmakers, scientific information is most often mobilized to assess the risks inherent in demands for the exploitation of natural resources (Chailleux, 2019). The production and dissemination of scientific information also attracts the attention of researchers in the field of communication studies who are interested in the popularization efforts deployed by scientists (Comfort \& Park, 2018) and by journalists who, depending on the country, place more or less importance on the dissemination of scientific information to address environmental issues (Bailey et al., 2014). In addition, some authors question the ambivalent role of scientific data in the context of environmental education (Berryman \& Sauvé, 2016; Busch, 2016). Whether science is acting in the balance of power between political decision-makers and economic actors (Boehmer-Christiansen, 1994), in the effort to raise public awareness of environmental issues or in the education of the young people, its role is intimately linked to the methods of production and dissemination of scientific data and the different actors don't pay attention in the same way at the results provided by scientific community. To better understand how and why the scientific ideas and reasoning can overpassed their role to provide objective data to the institution and the individual to better take decision, this article explores in which ways the young people's involved in environmental issue use scientific to argue in the context in which social media takes a significant place.

\section{STATEMENT OF THE PROBLEM Scientific Information and Training of Eco-Committed Citizens}

According to Davenport and Prusak, the "Knowledge is a fluid mix of framed experience, values, contextual information and expert insight that provides a framework for evaluating and incorporating new experiences and information" (1998: 5). Scientific knowledge can therefore be defined as a framework for the specific interpretation of the events and experiences, based on objectifying methodologies, responding to peer review criteria. If scientific information or data can be defined as 
the elements provide by the scientific community based on their research to strengthen the scientific knowledge, it is interesting to check whether the importance given to this scientific information or data always corresponds to a scientific treatment of information, that is to say that meets the criteria of objectification of the information and data used.

Some authors point out that the simple transmission of scientific information about the environment is insufficient to encourage the engagement of young people in environmental issue. Not only does a sensitive and direct experience of nature from childhood encourage engagement in adolescence or in adulthood (Chawla, 1998), but awareness of environmental issues by human intermediaries, such as parents or teachers, leads above all to an individualized commitment (Chawla, 2007). In other words, research has demonstrated that the dissemination of scientific information does not significantly lead to the engagement of populations in the defense of the environment (Allum et al., 2008) and that interpersonal relationships generally have more influence than scientists do on the perception of environmental issues (Roser-Renouf et al., 2014). It is not only the objectivity of the facts which plays a role here but the subjective implication of the individual in the relation to the other.

Researchers in the field of cultural studies in science education point out the limits of an "ecoscientist" school culture (Zeyer \& Kelsey, 2013). By favoring education based on the transmission of scientific information that would be difficult to question, many educational establishments unwittingly discourage young people from engaging in protecting the environment as they become convinced that they could no longer change the course of the future (Bader et al., 2017). The transmission of scientific information has even been found to contribute to an "environmental depression" among young people (Zeyer \& Kelsey, 2013). Conversely, knowing that global warming is real and that humans can reduce the threat promotes engagement in collective action to protect the environment (Krosnick et al., 2006). But some studies show that the certainty of a deterioration of the environment promotes engagement without being sufficient (Stern, 2011) and others authors belief in the effectiveness of this engagement remains crucial (Roser-Renouf et al., 2014). The information resulting from scientific research seems to play a role in the decision to commit or not on the condition that the disseminated data are interpreted from a framework giving them a meaning.

To understand the role of science in the decision of young people to get involved or not in favor of the environment, it is then important to check how this information is processed and used.

\section{Get informed and Get Involved in the ICT Era}

In recent years, social medias have become one of the main sources of information and thus one of the main channels for the dissemination of scientific news (SezenBarrie, Miller-Rushing, \& Hufnagel, 2020). While social medias promote online membership of activist groups (Conroy, Feezell, \& Guerrero, 2012; Koteyko, Jaspal, \& Nerlich, 2013; Kim, Hsu, \& de Zúñiga, 2013; Valenzuela, Arriagada, \& Scherman, 2012), facilitate the mobilization of people to participate in committed events (Musick \& Wilson, 2008) and increase the chances of being invited to participate in engaged activities (Musick \& Wilson, 2008; Wilks \& Harris, 2016), they also establish themselves as a significant tool for the dissemination of scientific information. Although the opinions of friends play an important role in young people's interpretation of the information that circulates on social medias (Vitak, Zube, Smock, Carr, Ellison, \& Lampe, 2011), the personal beliefs of these young people also play an significant role in how they deal with contradicting information on the internet (Corner et al., 2012). However, their beliefs have less impact when they are confronted with objective facts or figures rather than opinions (Corner et al., 2012). Some studies also note that individuals who use social media to obtain information are more likely than others to be already engaged on these subjects (McLeod, Scheufele, \& Moy, 1999). In addition, despite the online availability of scientific content, many interpretations of environmental issues remain incorrectamongyoung people(Shepardson, Niyogi, Choi, \& Charusombat, 2011; Taber \& Taylor, 2009). In this context, it is difficult to confirm whether social medias promote the engagement of young people or whether the engagement of young people promotes the use of social medias (Boulianne, 2009; 2011; 2015). If scientific information plays a role in the representation of environmental issues, and social medias have become one of the main tools for disseminating related them, it is hard to confirm the role of the scientific information circulating on the social network in the commitment of the young people. On one hand, they seem to benefit in the digital age from significant scientific knowledge, helping them to better understand the information provided by the scientific community. On other hand, the ease with which scientific data circulate among other more or less objective information questions us about the place they occupy in their representation and about the actual use that young people make of them. Does this scientific data circulating about environmental issue on social network seems too strengthen their scientific knowledge? Do the young people apply a critical point of view on 
this information provided to be sure they respect the scientific criteria? In other words, is scientific knowledge itself this framework for the interpretation and reception of scientific information or does scientific information escape this framework with its duty of objectification?

\section{METHOD \\ Research Design}

One of the ways to answer those questions is to analyze their representations of the information disseminated by the scientific community and more broadly to question them about science and scientists themselves. As part of a qualitative survey on the relationship of young French people to their commitment in environment issue (14-25 years old), we were particularly interested in the reasons for their commitments and explored their uses of social medias in connection with their decision. Our research is therefore oriented by two main objectives. First, it is about better understanding how young French people represent their commitment in favor of environment, by focusing on their definition of commitment, the reasons that motivate them and the actions they undertake. Second, it is about understanding their uses of the Internet and more specifically of social media in the context of their commitment. Concretely, the objective here is to question them about their reception and processing of information online, about their choice of whether or not to share information and/or to produce their own content on environmental issues.

\section{Research Environment and Participants}

As part of our research project about the young people's commitment linked to environmental issues, we contacted several groups involved in the organization of events to raise awareness of environmental issues as well as online groups of young people interested in this topic in France to meet young people involved in collective environmental action. In addition, we launched calls on social media to interview young people who said they were committed to the environment without being part of an activist group. This decision to bring together young people engaged collectively and individually is based on the work of Geoffroy Pleyers (2010), who highlights the individualization and recent privatization of the ecological commitment of young people. The common thread among the young people we spoke to was that they all declared themselves to be committed to defending the environment. During our contact with them, the young people were told that the research objective was twofold: to better understand the definitions and the boundaries of ecological commitment and to question the role of the Internet in the recognition of this commitment. We excluded from our panel the young people who work or get paid to take action in favor of environment.

In total, we selected 62 young people, including 30 adolescents ages 14-17 and 32 young adults ages 18-25, all of French nationality. The respondents consisted of 30 boys and 32 girls, among whom 23 of the 62 declared that they were not part of a group committed to ecology but were engaged all the same. Each respondent was interviewed once for a duration varying between 42 min and $80 \mathrm{~min}$. The interviews were carried out faceto-face and by videoconference to facilitate access to interviewees from all over France (excluding the French overseas departments and territories). Summary is included as an appendix to the article.

\section{Research Instrument}

The first part of the interviews was devoted to the definitions of commitment given by the young people to clarify with them which actions they considered to be signs of the beginning of their commitment to defending the environment. For example, we asked them "What do you think originally causes someone to take action for the environment?", and "What triggered in you this desire to get involved in ecology?", and question them about their representation of the constancy of their commitment with question as "Do you think that your actions are still true to your ecological values?". The second part was devoted to questions allowing us to better understand whether or not the reception, the diffusion and the production of online content can be considered committed actions. For examples, we asked "what do you think of the information you find on the internet about ecology?", "Can you explain how you get information about environmental issue from the web?" and "How do you decide whether or not to share information about environmental issues on social media?". No question were directly addressed the issue of science or scientific data. But the young people in the survey all spoke about their role in their engagement and their presence on social media.

\section{Data Gathering Procedures and Analysis}

All of the interviews were transcribed for analysis. Our analytical work was guided by an inductive approach, inspired by the stages of codification, categorization and connection as presented in the grounded theory of Glaser and Strauss (2009). We first carried out a careful labeling of the interviews to identify recurring units of meaning. Subsequently, we grouped these units of meaning to produce the most significant categories among the young people interviewed. It appeared that the category of science (that is to say, of the lexical field around scientific knowledge: the use of statistics, the use of figures, reading 
articles, interest in scientific journals and reports, etc.) was omnipresent in the speech of the adolescents and young adults. Returning to the content of the interviews, this time with the aim of finding the significant relationships between the category of science and other categories present in the speech of the respondents. This article presents and discuss these results to better understand what they can contribute to reflections on environmental education.

\section{Ethic}

According to the CNIL (Commission National de l'Informatique et des Libertés), the teenager's parent (Under 18 years old) sign a document to allowed them to respond our question. A copy of the list of the question was provided to them.

\section{RESULTS}

Whether their contact with science occurred through scientific personalities involved in the ecological movement or through reading reports like those produced by the Intergovernment Panel on Climate Change (IPCC), the scientific data play a role in the decisions of our respondents to become involved and strengthened their commitment. However, although scientific data and personalities from the world of science are at the center of their argument to explain their commitment, the emotional dimension is omnipresent in their speeches. As a result, scientific knowledge does not always seem to be the main framework for interpreting scientific data found on social media. The relationship with science of the young people implies both the mobilization of scientific background and a significant importance given to the emotion that the facts arouse. In other words, the engagement of these young people does not seem totally based on an objective relation to the facts, but rather on a sensitive interpretation of the scientific data.

\section{The Emotional Dimension of Scientific Information}

Focused on wind energy, Emma, 22, is preparing a master's degree in the management and trade of renewable energy. When we asked her if a particular event had encouraged her to become involved about environmental issue, she described how she was touched by the words of a scientific personality: "There was a scientist-I don't remember his name-who has very long, straight hair, who appeared on The Daily, who also made independent videos-I don't know what network it was with-and he said that the situation was catastrophic (...). I was struck by the fact that he looked so devastated; in fact, I felt that he was very touched. He said, 'Help, we have to wake up now!"”
Emma's example clearly shows how science or a scientific personality can play a role defined as being significant for the young people in the survey without being based on a rational use of the contributions of science and without named the source of the cited information (neither the name of the scientist, nor the name of the social media). On the other hand, the emotion felt by the scientist is for her central, and seems to largely explain the emotion felt by her. As the example of Emma shows, it is possible for respondents to cite a scientific personality without precisely remembering his identity and therefore without being able to identify the source of the remarks, while recognizing the significant role played by this personality in his commitment.

The emotion that the scientific personality or scientific data can arouse is significant for several young people in the survey when it comes to disseminating information in order to raise awareness among members of its networks. Zoe's example is a good illustration showing that some young people associate scientific information with their ability to arouse emotions.

"For example, on Instagram, as soon as I see something that touched me, which shows the extent that it has, or even that I find interesting well, I share it and I send it to friends, or else I share it outright in story. For example, I put statistics, videos of scientists, speeches, and videos of Brut compared to news about Black Friday." (Zoé, 16, environmental delegate in her classroom)

Science is foremost seen by young people in its potential for emotional appeal to oneself and to others. In our interviews, when participants' awareness of the urgency to act in favor of the environment was associated with the discovery of scientific facts, they did not describe it as a rationally made decision, but rather as a revelation, a sudden return to reality, a profound upheaval. In this context, it was not the depth of the argument and the rigor of the methodology that reinforced the authority of science in their eyes; instead, it was science's ability to strike the imagination.

These first two examples underline that we cannot reduce the context of interpretation of scientific data by the young people in our survey to a scientific knowledge that would need to be reinforced. A tension immediately emerges between, on the one hand, the desire to base one's engagement on objective facts, and, on the other hand, the need to feel affected, beyond the simple rational observation of a withdrawal of the environment. A first tension appears between the importance accorded to facts objectified by science and the importance of being touched by these same facts.

Difficulty in understanding the scientific content of, for example, reports or lectures sometimes explains why 
young people prefer short information on environmental issues that will quickly grab their attention. Instead of trying to read scientific articles or listen scientific discourse, it is easier to consult content who give them the main conclusion of a research. In this case, it is not the depth of the argument or the details of the methodology that strikes the imagination but the result that attracts attention and arouses interest, even outrage, anger or sadness.

Nadine, 18, who had the opportunity to meet Greta Thunberg at a rally in Brussels, stressed that the environmental leader similarly bases her legitimacy on her relationship to available scientific information easy to understand for the majority:

"Greta's sentences were short, clear, and simple. Because we often forget it, but in fact she repeats what scientists say, but in a super simple and super way, how to say, not scary, but direct, and it touched a lot of people, I think. So, I think it's the right method." (Nadine, 18, Friday for Future).

The interest in scientific information comes as a consequence of the curiosity of a generation of committed young people who are eager to access highly specialized content; however, this content can be difficult to access for those who have not been initiated into the field. That's why the accessibly of the scientific data is described as essential. But, in the same way, the transformation of scientific information into content easy to understand -that is to say, into easily transmitted and accessible content- implies to avoid the complexity of why it is scientific content. If the knowledge "provides a framework for evaluating and incorporating new experiences and information", in this case, this framework cannot be described as totally scientific. As Nadine and Emma say, the information disseminated as not to be only objective, but also able to reach the people, "to touch" them.

This importance given to the emotional dimension of scientific content allowed some young people to play a role in the dissemination of scientific information, even if they doubt about their legitimacy. Because their goal is not to inform first but to touch people, it is possible for them to provide information on the social media. Our respondents respect scientists because "they can, through information, speak more widely and reach more people" (Mathilde, 21, personal commitment). In this context, scientific data does not seem to have inherent value. Rather, the data becomes significant from the moment it is transmitted, which implies its transformation into content facilitate its dissemination. And this is the method that most of the young people interviewed employ to demonstrate their commitment on the social media: transmitting data by producing or disseminating accessible content to the largest audience possible.

Robin, 24 years old, living in Nantes, is very active on social media. He often produces short videos in which he highlights the environmental movement, sometimes using extracts from scientific reports or statistics from recent surveys. He recognizes that his work consists of highlighting specific information without respect to the rigor of the scientific method:

"In fact, it's not scientific information either; it's information for educational purposes I would say. I'm raising awareness about things that exist, just to shed light on them. But I don't produce qualitative content sourced with evidence and stuff like that. Me, it is rather awareness that I do at my humble level". (Robin, 24, Nantes, involved in associations)

Robin legitimizes his awareness-raising work by distinguishing it from that of scientists, since he believes that his methods and scientists' methods do not follow the same logic. They are not rigorous as the same level. They don't have the same requirements. Thus, Robin disseminates information regardless of whether it is "qualitative content sourced with evidence." As Robin, our respondents often compare themselves to scientists: They noted that scientists have a better grasp of the subjects than they do, have more mature thinking, have more acute critical senses, and have undergone training that qualified them as experts. The respondents repeatedly expressed recognition of the time that scientists devote to their work and the intelligence they demonstrate.

Unlike young people such as Robin-who attempts to raise awareness at the risk of having a questionable scientific basis for his publications-young people like Grégoire would rather refrain from creating and distributing content precisely because they do not consider themselves legitimate in the field. Young people like Gregoire, a 24-year-old from Lyon, would rather refrain:

"But it's true that I share very little information, and that's also why I tell myself that it's a shame because I still have a little experience. I'm probably not an expert. Finally, I do not claim at all the quality of expert on these subjects because already it may be areas that I explore a lot but it is not areas where I spend my life working on these subjects." (Grégoire, 24, personal commitment). While Grégoire also drew a comparison with the scientific field, he did so differently than Robin did. It was not his dissemination work that he compared to that of scientists; instead, he contrasted himself as a person from the figure of the expert. This comparison prohibits him from acting as he pleases.

For Robin and Gregoire, the feeling of being legitimate must therefore accommodate a comparison 
to the respected work of the scientific community, be it explicit or more subtle. The legitimacy of young people committed in environment issue is often built on a specific relationship to scientific knowledge. Sometimes, they are ready to share information because they accepted their own action is different than the scientific work. And sometimes, they don't thing they are allowed to play this role because they don't feel legitimate. The legitimacy seems to be strongly linked with the capacity to use or not the scientific information without trying to replace the expert, as Robin says. In this context, it is possible to use scientific data not to convince rationally like an expert should do, but from another register, for example, on the emotional level.

In summary, the mobilization of scientific data is therefore crossed by two tensions. First, young social media users must be situated on the "emotionobjectivity" axis, torn between the desire to "touch" the users of social media "quantitatively" (more people as possible) and qualitatively (deeper as possible) and the desire to preserve the scientific validity of the information. Secondly, they must find the right position on the "accessibility-complexity" axis: they must choose the form given to scientific data, at the risk of oversimplifying the available information. By situating themselves differently on these two axes, the young people in our survey revealed different ways of mobilizing scientific information in their engagement.

\section{The Logic of Buzz, Education, and Popularization}

When young people are at the extremes of "emotion" and "accessibility," they justify the instrumentalization of scientific data as a means to achieve their objective of reaching a large audience. What matters above all here is the form given to this data, as it runs the risk of not respecting the objectivity of the initial content. Zoé, 16 (Bordeaux, Environmental delegate in her classroom) pointed out that "in itself, the information I share can be true or false, but... after all, it is the feelings it can provoke and the information it can give to others that is important." Scientific information is then subject to the logic of the buzz, by the desire to reach emotionally social media users first before explaining them the situation with rational arguments

This logic of the buzz is not the only one, and the strategies of communication are numerous among our respondent. For example, several of them are moderators of accounts and official pages for ecological collectives. All of them publish scientific content, and they explained that they have to adapt the information to be more attractive to not intimidate people with their presentation. Margot, the 17-year-old moderator of the Instagram account
Youth For Climate of the Basque Country, seeks to make the content more aesthetically pleasing so that it draws readers; she does this to ensure that information the account shares is not lost in the flow of news feeds and that young people discover the scientific information the account publishes. But using scientific data in a buzz logic does not prevent some young people from using the same data according to other logic, as Simon, 18, indicates. Even if he regrets that sensationalism prevails at the expense of the quality of information, he explains that "it's a lot in the sensational and not always in the technical; it's a shame but normal because not everyone is able, me either, to approach the subjects from a slightly technical point of view (...). The information relayed is sensational. The IPCC report does not make 20,000 retweet on Twitter. A bit shocking information from a burning Koalas, which is very unfortunate, it will make 20,000. However, the two are important, perhaps not at the same level." (Simon, 18, Friday for Future). In this case, the main goal of the young people seems not to be to strengthen a scientific culture among their peers but rather to reach them on a emotional level by using attractive news.

On other occasions, young people find themselves at the extremes of "rationality" and "complexity" axis. Their interest in scientific data is then explained by their objective of educating the population. The logic of buzz is replaced here by the logic of education:

"There is DataGueule who is making a lot of effort, who put a lot of figures. We are going to be bombarded with figures for three minutes but suddenly we have all the sources in link and if we need to feed our words at a time we can completely transmit them because they have done a real job of research made available to people" (Clément, 17 , personal commitment).

In this context, the young people who disseminated scientific data seek to respect the standards of science even in the modes they select to communicate the results of scientific reports. What is targeted is access to content produced by the scientists themselves, as witnessed by many young people who have consulted IPCC reports. This may be part of a divide between the young people who seem able to access and understand-at least in part-scientific writings and the young people who give up due to the complexity of the writing.

When young people are at the extremes of "rationality" and "accessibility," it is the effort to educated their peer through science information who is the most important for them. The goal is to easily disseminated the scientific information and to reinforce scientific culture, without ever betraying the results products and sources cited. In this case, the young people concerned consider that even partial access to scientific data is capable of raising 
social media users' awareness. However, it is again the emotion aroused by the revelation of scientific data that remains significant. For most of the young people we met, like Anaïs, convincing is rarely only a question of argumentation calling out to reason:

"So I think that getting out of the figures with real studies is important but it is also important to touch the emotions, to explain to the person that climate change and pollution change us all and that in years if we do nothing I don't know what it will become but it can be worrying" (Anais, 16, personal commitment)

In the end, the popularization effort is expected and enlargement praised. The content making scientific data accessible finds a certain balance between the minimum respect for objectivity on the one hand and the need to reach the public on the other:

"Because it affects more people and that perhaps we will no longer identify with... well, I give an example, whatever, but there's HugoDécrypt that I'm a bit on YouTube, well, he's a student in Political Science, he makes videos every week of a few minutes where he retraces a bit of the big news of the week, that's it, I like it because he's a Sciences Po student, he's cool, and that it allows me to have minimal and a little light information of what is happening." (Marine, 23, personal commitment).

The logic of buzz, education and popularization always show the research by young people of the survey for a balance between the need to reach out to others and to maintain the objectivity of scientific data. Those logics coexist and most of the respondents seem to pass imperceptibly from one to another in their digital practices. By justifying different types of mobilization and dissemination of scientific information, especially through attractive content, these young people try to meet the imperative of quantitatively reaching a large number of people. In other words, different recipients respond to different presentations of scientific data:

"That there are people who will walk much more with emotion, and only by showing them photos of the damage that can cause different things that go against these ecological questions, just in their showing photos, and making the connection with global warming, etc., there are people who will walk very well with emotion and who, suddenly, will drink a little our words and feel concerned too. And conversely, there are people who are not going to walk at all with emotion and who are going to need concrete arguments, scientific evidence, statistics... So I think it will really depend on the audience." (Mathilde, 21, personal commitment).

Although the young people's interest in and respect for the scientific community is undeniable, and although the importance accorded to scientific data was significant in their conversations with us, respect for the principles of the scientific approach was not perfectly integrated into the young people's information practices and practices for broadcasting and producing youth content. Emotion is often both the gateway through which they themselves have been introduced to the importance of environmental issues and the means through which they can in turn initiate other young people, even if they do not master not perfectly complex scientific knowledge. This position is certainly interesting because it partly legitimizes them to engage in awareness-raising actions. On the other hand, the risk of granting emotion an importance to the point of contradicting the very principles of objectification of the data advocated by the scientific approach seems very present.

\section{DISCUSSION AND CONCLUSION}

Although the young people's interest in and respect for the scientific community is undeniable, and although the importance accorded to scientific knowledge was significant in their conversations with us, respect for the principles of the scientific approach was not perfectly integrated into the young people's information practices and practices for broadcasting and producing youth content. Thus, by working with young people on the basis of their interest in and respect for science, it is undoubtedly possible to support their commitment in the digital age. Despite their respect for science and scientists, young people's processing of scientific knowledge does not always seem to respect the standards of objectification advocated by the scientific approach. If the coexistence of the logics of buzz, education and popularization shows the search for a balance between appeal to reason and appeal to emotion, and between accessibility and intelligibility, it recalls the risk of succumbing to the desire to convince the greatest number to the detriment of scientific criteria advocating the objectivity of the approach taken. This can be problematic for at least two reasons. First, the importance given to the need to be touched can make the scientist more important than the data they produce. It is therefore no longer criteria of objectivity that risks legitimizing for some young people, but its ability to "reach" its audience. Personal characteristics such as charisma can then play a more important role than the objectivity of their approach in the evaluation of their speech. Second, because it is contradictory, using scientific data in an unscientific way opens the door to criticism from their detractors. In this case, helping the young people to be more efficient in their active role for promoting environmental issues means to support them for a more scientific and reflexive use of scientific data in general and of scientific content 
on the social media in particular.

Our survey allows us to put forward some hypotheses to better understand the posture of the young people we meet, and makes it possible to suggest a few avenues to better support these young people.

First, young people's desire for information comes up against the inaccessibility, even illegibility, of certain scientific knowledge, which is considered by some to be too complex. Thus, scientific information plays the role of intermediary, nourishing curiosity without necessarily satisfying it fully. One can hypothesize that the acquisition of a scientific culture is not easy because the scientific data available being very complex to understand and the means to acquire a solid scientific knowledge are not clearly identified by the young people. It would then be useful to produce intermediate content allowing the gradual transition from the basic scientific information to complex scientific knowledge. The idea would be to segment scientifically valid content, allowing young internet users to start with scientific news and progressively access more intermediate content, which would become increasingly complex, allowing them to ultimately access the sources produced by scientists themselves. YouTubers, who are sometimes already communicated scientific knowledge, could be called upon, but under expert supervision that could precisely avoid the temptation of the buzz.

Second, the interviews showed that young people question their legitimacy when they hesitate to share or create content on environmental issues. One can hypothesize that these questions and hesitations are partly due to the fact that to date, there is no commonly accepted methodology for disseminating or creating information on social media. Such a methodology should be thought out, constructed and taught to young people on the basis of at least four questions: Why is the information disseminated? To whom is it disseminated? What content do we broadcast? How do we broadcast? By seeking the answers to these questions with the young people themselves, it would then be a question of checking with them what role the appeal to emotions plays in the decisions to be made and to examine whether they come into tension with the need to respect the objectivity of scientific data. Thus, adults should provide an introduction to the processes of dissemination, production and objectification of content to groups of young people engaged to help them determine how one can legitimately talk about environmental issues without being an expert. Beyond a rigorous content distribution and production methodology, raising awareness of environmental issues would involve exploring the ethical dimension of the distribution and production of online content with young people. This can contribute to make the scientific knowledge a stronger interpretative framework for scientific information among young people.

Our research did not have as main objective to analyze the relationship of young people to science but rather the various ways of involving in their engagement the available information, in particular on social media. While our results have enabled us to discuss the relationship of young people to scientific data, research geared more specifically to this subject could inform us more about the risks linked to the role of emotion in the processing of information in the context of ecological commitment and on the representations of scientific personalities by young people involved in this field. Our results enabled us to evoke that scientists seem to occupy an important place in the representations of young people, not only because they are producers of reliable data, but also because they have the qualities of speaker, a charisma that facilitates access to their speech. Similar qualities are sometimes mentioned when talking about YouTubers: it is no longer the content that is most important, nor the form for that matter, but the personality of the person carrying the message. More specific surveys on these people, their quality and their discourse, by, for example, comparing them and their role, could be useful, both to inform us more about what attracts and appeals to young people, but also to verify the limits of their capacity to promote engagement, or even the excesses carried by these people who make "scientific news" at the digital era.

\section{REFERENCES}

Allum, N., Sturgis, P., Tabourazi, D., \& Brunton-Smith, I. (2008). Science knowledge and attitudes across cultures: A metaanalysis. Public Understanding of Science, 17(1), 3554. https://doi.org/10.1177/0963662506070159

Bader, B., Orellana, I., Sauvé, L., \& Villemagne, C. (Éds.). (2017). Éducation, environnement, écocitoyenneté: Repères contemporains. Presses de l'Université du Québec.

Bailey, A., Giangola, L., \& Boykoff, M. T. (2014). How grammatical choice shapes media representations of climate (Un) certainty. Environmental Communication, 8(2), 197215. https://doi.org/10.1080/17524032.2014.906481

Berryman, T., \& Sauvé, L. (2016). Ruling relationships in sustainable development and education for sustainable development. The Journal of Environmental Education, 47(2), 104117. https://doi.org/10.1080/00958964.2015.1092934

Boehmer-Christiansen, S. (1994). Global climate protection policy: The limits of scientific advice. Global Environmental Change, 4(3), 185200. https://doi.org/10.1016/09593780(94)90002-7

Boulianne, S. (2009). Does internet use affect engagement? A meta-analysis of research. Political Communication, 26(2), 193211. https://doi.org/10.1080/10584600902854363

Boulianne, S. (2011). Stimulating or reinforcing political interest: Using panel data to examine reciprocal effects 
between news media and political interest. Political Communication, 28(2), 147162. https://doi.org/10.1080/1058 4609.2010.540305

Boulianne, S. (2015). Social media use and participation: Ametaanalysis of current research. Information, Communication \& Society, 18(5), 524538. https://doi.org/10.1080/136911 8X.2015.1008542

Busch, K. C. (2016). Polar bears or people? Exploring ways in which teachers frame climate change in the classroom. International Journal of Science Education, Part B, 6(2), 137165. https://doi.org/10.1080/21548455.2015.1027320

Chailleux, S. (2019). Strategic ignorance and politics of time: How expert knowledge framed shale gas policies. Critical Policy Studies, 119. https://doi.org/10.1080/19460171.2018. $\underline{1563556}$

Chawla, L. (1998). Significant life experiences revisited: A review of research on sources of environmental sensitivity. The Journal of Environmental Education, 29(3), 1121. https:// doi.org/10.1080/00958969809599114

Chawla, L., \& Cushing, D. F. (2007). Education for strategic environmental behavior. Environmental Education Research, 13(4), 437452. https://doi.org/10.1080/13504620701581539

Comfort, S. E., \& Park, Y. E. (2018). On the field of environmental communication: a systematic review of the peer-reviewed literature. Environmental Communication, 12(7), 862875. https://doi.org/10.1080/17524032.2018.1514315

Conroy, M., Feezell, J. T., \& Guerrero, M. (2012). Facebook and political engagement: A study of online political group membership and offline political engagement. Computers in Human Behavior, 28(5), 15351546. https://doi.org/10.1016/j. chb.2012.03.012

Corner, A., Whitmarsh, L., \& Xenias, D. (2012). Uncertainty, scepticism and attitudes towards climate change: Biased assimilation and attitude polarisation. Climatic Change, 114(34), 463478. https://doi.org/10.1007/s10584-012-0424-6

Davenport, T., \& Prusak, L. (1998). Working Knowledge (Harvard Business School). Harvard Business School.

Glaser, B. G., \& Strauss, A. L. (2009). The discovery of grounded theory: Strategies for qualitative research. Aldine.

Kim, Y., Hsu, S.-H., \& de Zúñiga, H. G. (2013). Influence of social media use on discussion network heterogeneity and civic engagement: The moderating role of personality traits: social media \& personality traits. Journal of Communication, 63(3), 498516. https://doi.org/10.1111/jcom.12034

Koteyko, N., Jaspal, R., \& Nerlich, B. (2013). Climate change and 'climategate' in online reader comments: A mixed methods study: Climate change and 'climategate' in online reader comments. The Geographical Journal, 179(1), 7486. https:// doi.org/10.1111/j.1475-4959.2012.00479.x

Mcleod, J. M., Scheufele, D. A., \& Moy, P. (1999). Community, communication, and participation: The role of mass media and interpersonal discussion in local political participation. Political Communication, 16(3), 315336. https://doi. org/10.1080/105846099198659

Musick, M. A., \& Wilson, J. (2008). Volunteers: A social profile. Indiana University Press.

Pleyers, G. (2010). Alter-globalization: Becoming actors in the global age. Polity.

Roser-Renouf, C., Maibach, E. W., Leiserowitz, A., \& Zhao, X. (2014). The genesis of climate change activism: From key beliefs to political action. Climatic Change, 125(2), 163178. https://doi.org/10.1007/s10584-014-1173-5

Sezen-Barrie, A., Miller-Rushing, A., \& Hufnagel, E. (2020). 'It's a gassy world': Starting with students' wondering questions to inform climate change education. Environmental Education Research, 26(4), 555576. https://doi.org/10.1080/ 13504622.2019.1610158

Shepardson, D. P., Niyogi, D., Choi, S., \& Charusombat, U. (2011). Students' conceptions about the greenhouse effect, global warming, and climate change. Climatic Change, 104(34), 481507. https://doi.org/10.1007/s10584-009-9786-9

Stern, P. C. (2011). Contributions of psychology to limiting climate change. American Psychologist, 66(4), 303314. https://doi.org/10.1037/a0023235

Taber, F., \& Taylor, N. (2009). Climate of Concern-A Search for Effective Strategies for Teaching Children about Global Warming. International Journal of Environmental and Science Education, 4(2), 97-116.

Valenzuela, S., Arriagada, A., \& Scherman, A. (2012). The social media basis of youth protest behavior: The case of Chile. Journal of Communication, 62(2), 299-314. https://doi. org/10.1111/j.1460-2466.2012.01635.x

Vitak, J., Zube, P., Smock, A., Carr, C. T., Ellison, N., \& Lampe, C. (2011). It's complicated: Facebook users' political participation in the 2008 election. Cyberpsychology, Behavior, and Social Networking, 14(3), 107114. https://doi. org/10.1089/cyber.2009.0226

Wilks, L., \& Harris, N. (2016). Examining the conflict and interconnectedness of young people's ideas about environmental issues, responsibility and action. Environmental Education Research, 22(5), 683696. https:// doi.org/10.1080/13504622.2015.1054261

Zeyer, A., \& Kelsey, E. (s. d.). Environmental education in a cultural context. In International Handbook of Research on Environmental Education (Routledge, p. 206212). 